\title{
Analysis of Laminated Architectural Glazing Subjected to Wind Load and Windborne Debris Impact
}

\author{
Mahesh S. Shetty, Lokeswarappa R. Dharani, and Daniel S. Stutts \\ Department of Mechanical and Aerospace Engineering, Missouri University of Science and Technology, Rolla, MO 65409-0050, USA \\ Correspondence should be addressed to Lokeswarappa R. Dharani, dharani@mst.edu
}

Received 9 June 2012; Accepted 30 July 2012

Academic Editors: X. Li and I. Raftoyiannis

Copyright ( $) 2012$ Mahesh S. Shetty et al. This is an open access article distributed under the Creative Commons Attribution License, which permits unrestricted use, distribution, and reproduction in any medium, provided the original work is properly cited.

\begin{abstract}
During windstorms and hurricanes, architectural glazing is subjected to wind loading and windborne debris impact. Wind-borne debris is categorized into two types. One is small hard missile like roof gravel and the other is large soft missile representing the lumber from wood-framed buildings. Laminated architectural glazing (LAG) is the commonly used glazing in buildings where impact resistance is needed. The prefailure stress response of the LAG due to the combined loading due to wind and windborne debris impact is studied. Following the ASTM standards (E1886 and E1996), a steel ball with an impact velocity of $39.62 \mathrm{~m} / \mathrm{s}$ and a wooden cylinder with an impact velocity $12.19 \mathrm{~m} / \mathrm{s}$ were chosen to be representative of small and large missiles, respectively. A lateral pressure that corresponds to a wind speed of $58.11 \mathrm{~m} / \mathrm{s}$ was used to represent wind loading on LAG. The effect of geometric and material properties on the stress response of a rectangular LAG is studied parametrically. Thinner outer ply would result in better prefailure stress pattern than a thicker outer ply, while thicker interlayer generally results in lower stresses in failure critical areas. The contribution of wind loading to the principal stress is between $5-10 \%$ of the combined stress with small missile case having higher percentage.
\end{abstract}

\section{Introduction}

Architectural glazing is highly vulnerable during windstorms, particularly hurricanes, due to wind pressures and associated wind-bone debris. Hurricane Ike in 2008 provided a testament to the damage that can result to the interiors of buildings if the glazing envelope is breached (http://en .wikipedia.org/wiki/Hurricane_Ike). The typical wind load acting on the glazing during these windstorms can be attributed to turbulent wind, changes in the direction of wind, and also its duration. Typical windborne missile constitutes roof gravel, roof tiles, pieces of lumber, and materials from damaged structures.

Beason et al. [1] studied the impact of hurricanes on the glazing damage in the downtown area of Houston, TX, USA. In their observation, the glazing damage was found to be mainly due to windborne roof gravel from building roofs and they recommend using laminated glass for architectural glazing. Laminated glass consists of two soda-lime glass plies held together by an interlayer, which is an adhesive polymer.
PVB (polyvinyl butyral) is the commonly used interlayer. According to Beason et al. [1], the outer layer, which is exposed to the wind and debris loads functions as a "sacrificial ply" and is allowed to break, whereas the inner layer remains intact thus protects the integrity of the building interiors. Also, the broken glass adheres to the PVB, thus preventing injury from flying shards of glass. Extensive field evidence has been collected after hurricanes and other windstorms with high-sustained winds and turbulent gusts from the early 1970 s to the present. This field evidence has documented the mechanisms of windborne debris transport during windstorms and how its combined effect with wind pressures can lead to breaches in the building envelope and extensive property loss. Windborne debris generated during severe windstorms varies greatly, depending upon wind speed, height above the ground, terrain, surrounding structures, and other sources of debris [2].

Many researchers have studied the effect of wind loads or windborne debris on laminated architectural glazing. Flocker and Dharani [3-6] simulated the low velocity, small 
missile impact on laminated architectural glazing (LAG). Their study included stress response of the LAG to different PVB properties and geometry of glass plies [3], fracture of glass plies [4], interply debonding [5], and the impact resistance of various LAG configurations [6]. Vallabhan and Chou [7] studied the stresses and displacements developed in window glass systems of different aspect ratio which are subjected to static wind load. An iterative procedure was developed which incorporated nondimensional curves relating central deflections, maximum principal stresses, and lateral design wind pressures. Duser et al. [8] conducted a stress analysis and failure probability analysis of laminated glazing subjected to uniform lateral pressure. Dharani et al. [9] developed an analytical model to predict the cumulative probability of damage of inner glass ply due to small missile impact. The outer ply was modeled as a sacrificial ply, and a subroutine was incorporated in the finite element code DYNA2D by modifying it to incorporate the Hertz cone crack propagation in the outer glass ply. The postbreakage mechanical behavior was incorporated into DYNA2D using an algorithm subroutine. Ji et al. [10] studied the damage probability of outer ply due to steel ball impact in LAG system. The damage probability was found using a finite element model in combination with a statistical failure prediction model. Kaiser et al. [11] conducted a series of experiments using sacrificial ply design for LAG to find the damage probability of inner ply due to $2 \mathrm{~g}$ steel ball impact. In the case of sacrificial ply design the outer ply is allowed to break. Their [11] study revealed that the thickness of inner glass ply and PVB has a bearing on the impact resistance of the inner glass ply. The outer ply has less effect. Tsai and Stewart [12] studied the stress and deflection characteristics of large plates undergoing large defections due to wind load through a series of experimental tests and finite element simulations on glass plates of different geometric configuration. Saxe et al. [13] performed a series experiments as part of a study to develop the "sacrificial ply" design concept. The missile (steel ball) size, inner and outer ply thickness, and type were varied to determine their effects on the impact resistance of the inner ply. They [13] concluded that a LAG constructed with heat-treated or fully tempered inner plies, regardless of outer ply type, would have better impact resistance than LAG constructed with annealed glass plies. Saxe et al. [13] listed different components of the laminated glazing in the order of their importance to impact resistance and they further found that the inner glass ply type and its thickness were most critical.

Earlier studies report the response of architectural glazing either to wind load or debris impact separately. Also, extensive studies have been done to investigate the response of architectural glazing to small missile impact as opposed to large missile impact. Dharani and Yu [14] conducted a limited study of large missile impact, restricted to laminated glass of circular plate configuration. Since rectangular plate is the commonly used glazing configuration, a rectangular configuration is investigated in this study.

The principal objective of the current study is to investigate impact-induced stress propagation through a rectangular laminated architectural glazing under the combination of wind and debris impact loading and determine material and geometric properties that reduce the possibility of inner ply failure. It is assumed that low-velocity impact is such that the outer ply does not fracture. Cracks in glass surfaces tend to open and extend at the location of maximum tensile stress [3]. Glathart and Preston [15] and Dharani et al. [16] have already shown for small and large missile impact, respectively, that the critical area for fracture is the bottom surface of the inner ply of the LAG. Because "sacrificial ply" design does not permit fracture of the inner ply, this study in particular deals with finding the maximum tensile stress at the center of the bottom surface of the inner ply.

\section{Impact Problem Description}

Windborne debris, as per ASCE building codes [17], has been classified into two categories based on its mass and elastic modulus properties with respect to the glass. The small hard missile represents the roof gravel and the large soft missile represents timber from buildings and trees. Small missile impact is of concern at typical building elevation $(>30 \mathrm{ft}(9.1 \mathrm{~m}))$, whereas large missiles are of more concern at lower elevations. As per ASTM standard E1886 [18], a $2 \mathrm{~g}(0.004 \mathrm{lb})$ steel ball is chosen to be representative of a small missile with an impact velocity of $39.62 \mathrm{~m} / \mathrm{s}$. From ASTM standard E1996 [19], three large missile types are recommended. The missile configuration is as specified in Table 1. The wind load calculated for the small and large missile impact is based on the maximum wind speed and the type of area or surroundings. A wind speed of around $130 \mathrm{mph}(58.11 \mathrm{~m} / \mathrm{s})$ is considered, and the area is assumed to be dotted with public utility facilities. It may be noted that the impact velocities for both types of missiles are considerably lower than the wind speed. For the large missile, a circular cross-section is used instead of the rectangular cross-section specified in the standards in order to make the problem computationally more tractable. In the case of large missiles with rectangular cross section, the problem has to be analyzed for different orientations with respect to the plane of glass. Hence, to simplify the analysis, a circular cross section is chosen because it is symmetrical about the length axis of the missile. Large missiles, having both flat and round impacting end, are included in the present study.

The schematic of a rectangular laminated architectural glazing panel under wind and missile impact is illustrated in Figure 1. The normal impact of missiles or windborne debris impact occurs at a velocity $V_{o}$. The laminated panel is comprised of two soda lime glass layers with a PVB interlayer. The thicknesses of the outer and inner glass layers are denoted by $h_{o}$, and $h_{i}$, respectively, and the PVB interlayer by $h_{p}$. The glazing is simply supported on all sides without any in-plane end constraints. The loading system involves a uniform static pressure due to wind load and an impact due to the wind-borne debris. The loading is done sequentially with static wind load followed by the debris impact load rather than superposing the two cases. Ghrib and Tinawi [20] conducted seismic analysis of concrete gravity dams by first analyzing the response of dam due to its weight and hydrostatic pressure of the reservoir on the upstream wall 
TABLE 1: Baseline data.

\begin{tabular}{ll}
\hline & Parameters and properties \\
\hline Glass & $E=72 \mathrm{GPa}, \rho=2500 \mathrm{~kg} / \mathrm{m}^{3}, v=0.25$ \\
PVB & $G_{o}=1 \mathrm{GPa}, G_{\infty}=0.69 \mathrm{MPa}, \rho=1100 \mathrm{~kg} / \mathrm{m}^{3}, \beta=12.6 \mathrm{~s}^{-1}$, \\
Steel ball $[2 \mathrm{~g}]$ & $E=2.5714 \mathrm{GPa}, \nu=0.2857$ \\
Wooden cylinder $[2050 \mathrm{~g}]$ & $E=200 \mathrm{GPa}, \nu=0.29, \rho=7800 \mathrm{~kg} / \mathrm{m}^{3}$ \\
(Douglas Fir) & $E_{r}=1 \mathrm{GPa}, E_{\theta}=737 \mathrm{MPa}, E_{z}=14.74 \mathrm{GPa}, v_{r \theta}=0.39, v_{\theta z}=0.036, v_{z r}=0.029, \rho=505 \mathrm{~kg} / \mathrm{m}^{3}$ \\
Impact velocity & $G_{r \theta}=103.2 \mathrm{MPa}, G_{\theta z}=943.4 \mathrm{MPa}, G_{z r}=1.15 \mathrm{GPa}$ \\
& Small missile (Steel ball): $39.6 \mathrm{~m} / \mathrm{s} ;$ Large missile (Wooden cylinder): $12.19 \mathrm{~m} / \mathrm{s}$ \\
Plate dimensions & Panel area: Length $=1.55 \mathrm{~m}$; breadth $=1.1 \mathrm{~m}$ \\
& Inner ply thickness, $h_{i}=4.76 \mathrm{~mm}$ \\
& Outer ply thickness, $h_{o}=4.76 \mathrm{~mm}$ \\
Missile dimensions & PVB interlayer thickness, $h_{p}=1.52 \mathrm{~mm}$ \\
& Steel ball: $R=3.96875 \mathrm{~mm}$ \\
& Wooden cylinder: $R=32.81 \mathrm{~mm}$; length $=1.2 \mathrm{~m}$ \\
\hline
\end{tabular}

prior to earthquake excitation. A similar approach is adopted here. The interlayer bond is assumed to be perfect with no debonding or slipping during impact. Flocker and Dharani [5] have shown that the debonding between glass plies and the PVB has very little effect on the stress pulse shape and the peak critical stress in glass plies so the above assumption (no debonding) should have no material effect on the results to follow.

2.1. Material Models. In general, the stress tensor for the impact problem is computed as the sum of deviatoric and volumetric components

$$
\sigma_{i j}=S_{i j}-p \delta_{i j},
$$

where $\sigma_{i j}$ is the stress tensor, $S_{i j}$ is the deviatoric stress tensor, $p=-\sigma_{k k} / 3$ is the pressure, and $\delta_{i j}$ is the Kronecker delta.

The glass plies and small missile (steel ball) are modeled as isotropic, linear elastic, whereas the large missile (wooden cylinder) is modeled as orthotropic and linear elastic. The deviatoric and volumetric behavior is given by

$$
\begin{gathered}
S_{i j}=\left[\frac{E \nu \varepsilon_{\nu}}{(1+\nu)(1-2 \nu)}+p\right] \delta_{i j}+\frac{E \varepsilon_{i j}}{1+\nu}, \\
p=\frac{-E \varepsilon_{\nu}}{3(1-2 v)},
\end{gathered}
$$

where, $E$ is Young's modulus, $\varepsilon_{i j}$ is the strain tensor, $\nu$ is Poisson's ratio, and $\varepsilon_{\nu}\left(=\varepsilon_{k k}\right)$ is the volumetric strain.

The PVB interlayer was modeled as linear viscoelastic in the earlier study [3] of laminated glazing. Most recent work on laminated glazing [21] has shown that PVB can be modeled as linear elastic by using the short-term shear modulus $G_{o}$, and bulk modulus, $K$, to give the elastic constants, Young's modulus, $E_{p}$, and the Poisson's ratio, $v_{p}$, as

$$
\begin{gathered}
E_{p}=\frac{9 K G_{o}}{3 K+G_{o}}, \\
v_{p}=\frac{3 K-2 G_{o}}{6 K+2 G_{o}} .
\end{gathered}
$$

2.2. Design Wind Pressure. The ASCE standards [17] provide three methods to calculate the design loads, a simplified procedure, an analytical procedure, and wind tunnel procedure. In the simplified procedure, the values are directly plugged from standard tables, which do not require computations as in the case of analytical procedure. It is applicable for low-rise buildings only. For analytical procedure, buildings of regular shape are a requirement. If the buildings are of unusual shapes, which warrant accurate testing for wind loads, wind tunnel procedure is used. The design wind pressure, derived by the analytical procedure, is given by [17]

$$
p=q G C_{p}-q_{i} G C_{p i} \quad\left(\frac{N}{m^{2}}\right),
$$

where $q$ is the pressure at height above the ground, $G$ is the gust factor, and $C_{p}$ is the pressure coefficient. The term $q G C_{p}$ in the above equation refers to external wind pressure acting on the glazing. The term $q_{i} G C_{p i}$ refers to pressure inside the building and is taken to be zero. The gust effect factor accounts for the loading effects in the wind direction due to wind turbulence structure interaction. The basic velocity pressure [17], $q$, is given by

$$
q=0.00256 K_{z} V^{2} I,
$$

where $K_{z}, V$, and $I$ denote the velocity pressure coefficient, wind velocity, and importance factor, respectively. The importance factor accounts for the degree of hazard to human life and damage to property. The pressure coefficient denotes the actual loading on each surface of the building as a function of wind direction.

\section{Finite Element Modeling}

The problem is simulated in finite element code ABAQUS [22]. The dynamic problem is solved numerically using ABAQUS EXPLICIT with automatic time step increment and with contact surfaces defined to prevent penetration. Only one-quarter of the laminated glass panel is studied due to $x$ axis and $y$-axis symmetry. The mesh is varied to check for 


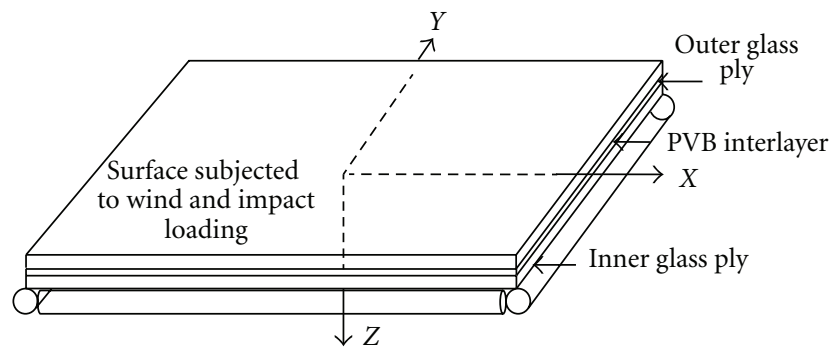

(a)

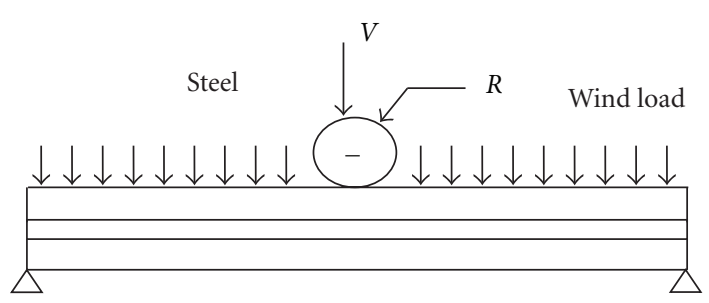

(b)

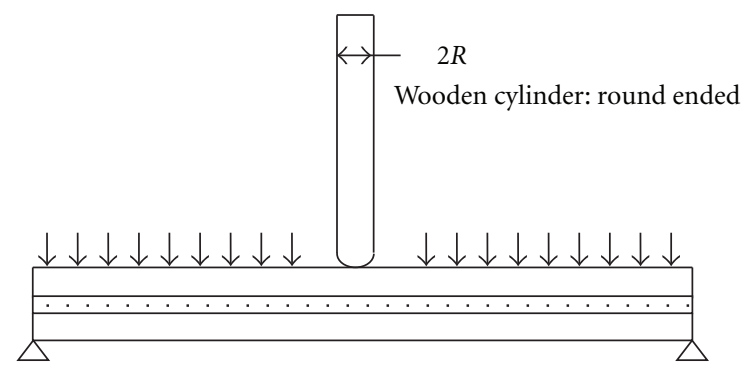

(c)

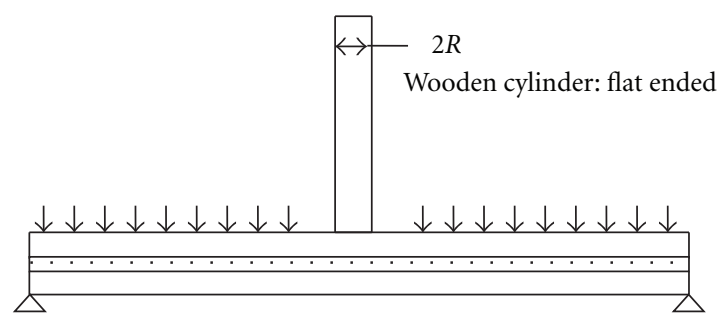

(d)

FIgURE 1: Schematic of laminated glazing with different missile types impacting it: (a) 3D profile of laminated glazing; (b) small missile; (c) large missile with round impacting end; (d) large missile with flat impacting end.

convergence of the maximum principal stress at the center of the bottom surface of the inner ply of the laminated glazing, which is the point of interest in this study. The optimized mesh has 12 elements through the thickness of the laminated glass panel with five each for glass panels and two for PVB interlayer and $100 \times 70$ elements along $x$ - $y$ plane across all layers in the laminated glazing. The meshing is biased that is mesh becomes finer towards the center of the panel, which is the impact area. The mesh also progressively goes fine along the thickness towards the top and bottom layer. No biased meshing is used for the PVB interlayer. Surface-to-surface contact is defined at the impact area between the missile and the top layer to prevent node penetration. Using kinematic contact algorithm, which ensures no missile penetration into the glazing, enforces contact between the two layers. The laminated glazing is modeled using eight-node linear brick solid elements (C3D8I) with full integration and no hourglass modes. The missiles are modeled using eightnode linear brick solid elements (C3D8R) with reduced integration and hourglass control. These elements define bending accurately. The static analysis is initially done using ABAQUS STANDARD to model the static wind load. The analysis is continued in ABAQUS EXPLICIT to model the debris impact with the wind load still applied to the glazing for the duration of impact. The IMPORT option is used to transfer the stresses and displacements at the end of static analysis to the dynamic analysis step. The baseline data used in this study are listed in Table 1.

\section{Results and Discussion}

The main objective of this work is to study the stress response of rectangular laminated architectural glazing to different impact loads, geometry, and material properties of the laminated glazing under combined loading. Then, determine the properties that reduce the possibility of inner ply fracture. Earlier studies report the response of architectural glazing to wind or debris impact separately. A large majority of earlier work was restricted to studying the response of architectural glazing to small missile impact. In the previous study of large missile impact by Dharani and Yu [14], only circular glazing configuration was considered for computational simplicity. Since rectangular configuration is the most commonly used in windows and no investigation has been done using this glazing configuration so far, a rectangular glazing configuration is adopted for this study. The baseline case is so chosen as to represent a typical architectural glazing impact situation. The response of the architectural glazing is studied by varying the thicknesses of the inner ply, outer ply, and PVB interlayer. This was done to determine the material and geometrical properties that reduce the possibility of inner ply fracture and thereby provide a qualitative assessment of impact resistance of various LAG configurations. The PVB viscoelastic constants, the short time shear modulus, $G_{o}$, and bulk modulus, $K$, are varied in the ranges $10 \mathrm{MPa}-1 \mathrm{GPa}$ and $0.35 \mathrm{GPa}-10 \mathrm{GPa}$, respectively. The impact durations for small and large missile impact are in the range of $10^{-5}-10^{-3}$ seconds. PVB behaves like a glassy solid in this range and hence it is modeled as a linear elastic material. As a result, long-time shear modulus $G_{\infty}$ is not taken into account.

Figures 2 and 3 show the time history plots of maximum principal stress $\left(\sigma_{1}\right)$ at the center of the bottom surface of inner ply for small missile and large missiles, respectively. The stress versus time plots show maximum principal stress for different values of short-term shear modulus of PVB. The PVB being assumed as linear-elastic, from (3), it is seen that the value of Young's modulus increases with the increase in short-term shear modulus. With higher stiffness, the stress response is lower. This is typical for all the cases studied. From Figure 2, the maximum peak stress for small missile occurs at around $10-15 \mu$ s after the initial impact. In the case 


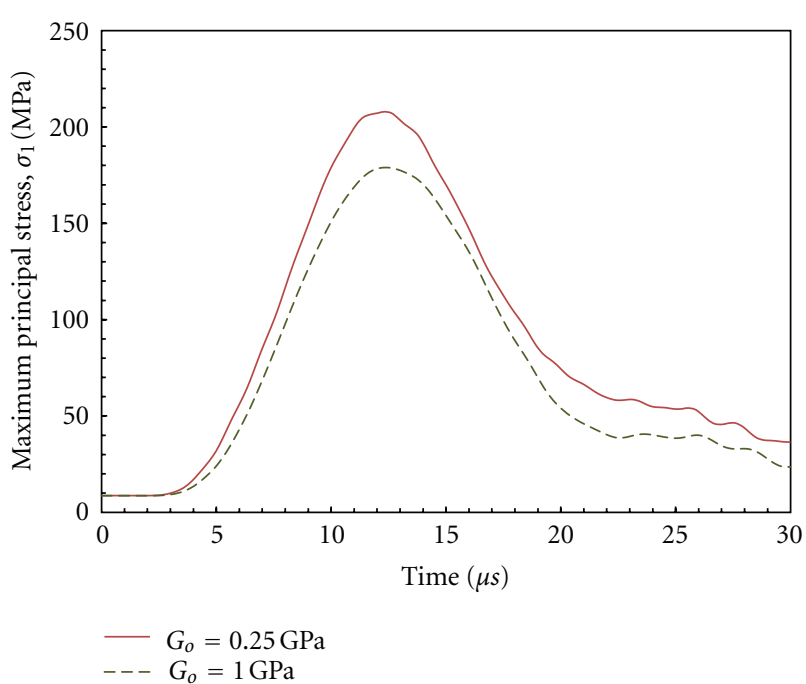

Figure 2: Effect of short-term shear modulus, $G_{o}$, on maximum principal stress on the bottom surface of the inner ply as a function of time after impact for a small missile impact at a velocity of $39.62 \mathrm{~m} / \mathrm{s}$.

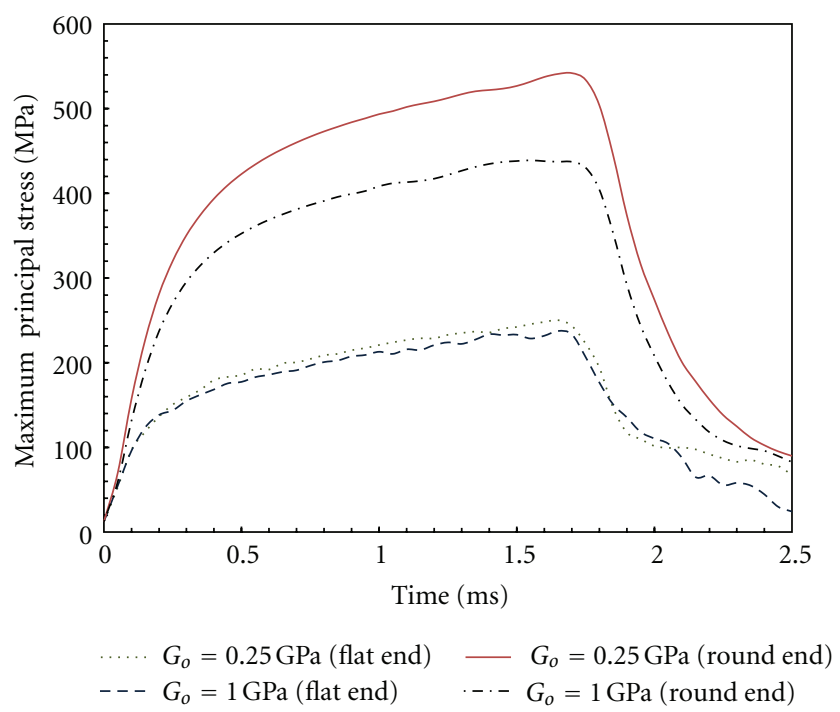

FIGURE 3: Effect of short-term shear modulus, $G_{o}$, on maximum principal stress on the bottom surface of the inner ply as a function of time after impact for a large missile impact at a velocity of $58.11 \mathrm{~m} / \mathrm{s}$.

of large missile, Figure 3 shows that the peak stress occurs around 1.5-2 ms for both flat and round end configurations.

The effect of inner and outer ply thicknesses on maximum principal stress at the center of the bottom surface of inner ply is shown in Figures 4 and 5. Here, the plots are generated by varying the thicknesses of outer or inner plies but maintaining other parameters at their respective baseline values. The ply thicknesses considered are consistent with the range of thicknesses tested by Saxe et al. [13]. Both plots in Figures 4 and 5 show similar trends: a region of high return for added thickness (or high penalty for reduced thickness)

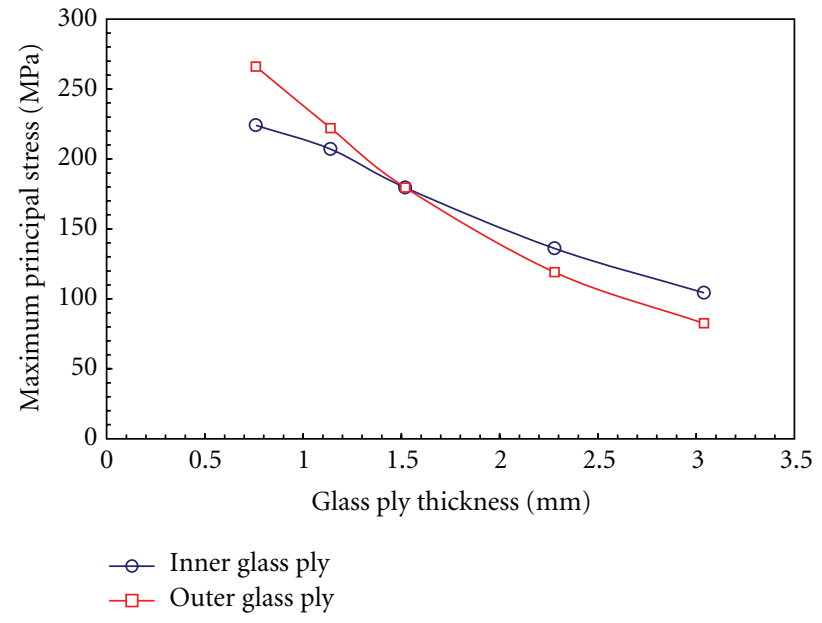

FIGURE 4: Effect of inner and outer glass ply thicknesses on maximum principal stress on the bottom surface of inner ply for small missile impact at a velocity of $39.62 \mathrm{~m} / \mathrm{s}$.

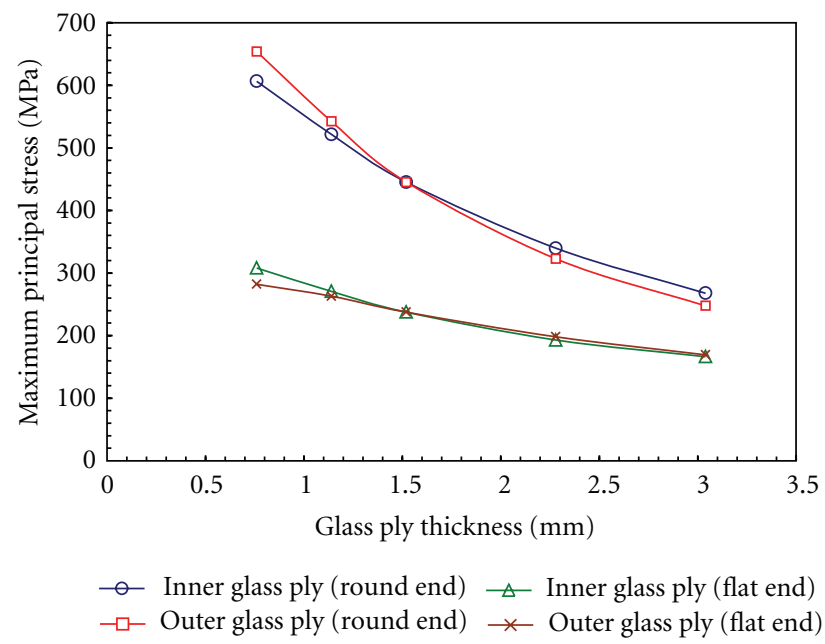

Figure 5: Effect of inner and outer glass ply thicknesses on maximum principal stress at the bottom surface of the inner ply for a large missile impact at a velocity of $58.11 \mathrm{~m} / \mathrm{s}$.

in which maximum principal stresses reduced significantly followed by a region where added thickness does little to further reduce the stress. The stresses for small missile and large missile with round end are higher when the outer ply thickness is reduced than in the case of large missile with flat end where the stresses are high upon reducing the inner ply thickness. This difference is attributable to the type of load various missiles impart to the panel at contact surface. The small missile and large missile with round end impart concentrated load, while the large missile with flat end imparts a distributed load.

The baseline material properties listed in Table 1 represent typical values widely used in various analyses and practices. However, there is a certain amount of uncertainty in these values. Figures 6 and 7 show the effects of PVB interlayer thickness on the maximum principal stress for 


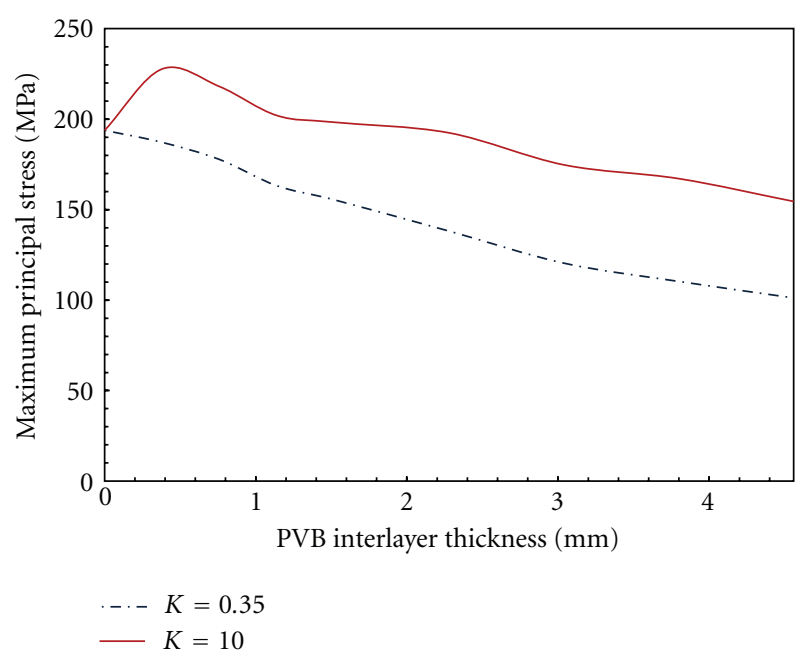

FIGURE 6: Effect of PVB interlayer thickness on maximum principal stress at the bottom surface of the inner ply for a small missile impact at a velocity of $39.62 \mathrm{~m} / \mathrm{s}$.

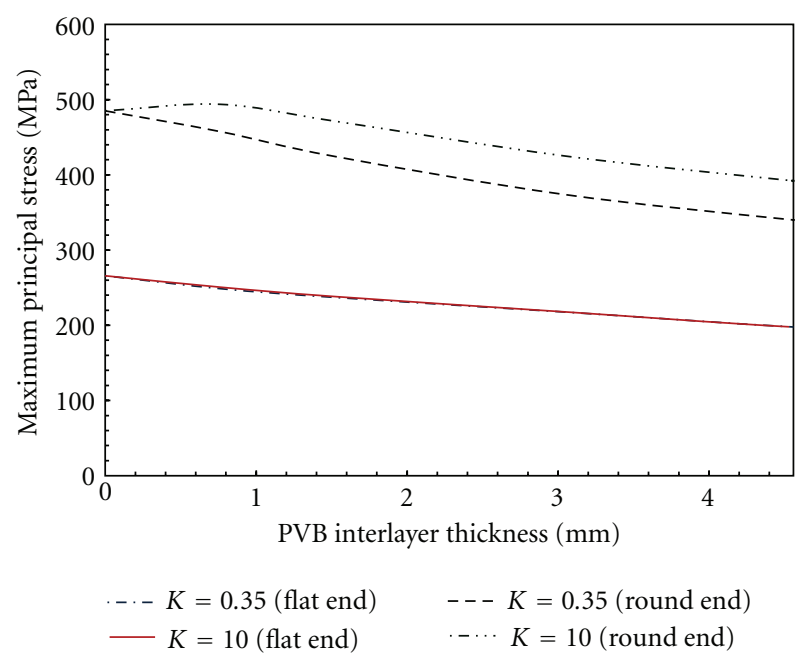

Figure 7: Effect of PVB interlayer thickness on the maximum principal stress at the bottom surface of the inner ply for large missile impact at a velocity of $58.11 \mathrm{~m} / \mathrm{s}$ for two bulk modulus $(K)$ values.

three different values of PVB bulk modulus. Overall, the trend is a reduction in maximum principal stress upon increasing PVB thickness. The effect of bulk modulus is more pronounced in case of small missile impact than large missile. For the small and the round-ended large missile cases, at the higher values of bulk modulus, increasing PVB thickness for very thin interlayer initially causes an increase in the maximum principal stress before a reduction takes place. The large missile with flat end is insensitive to variation of bulk modulus values.

Figures 8 and 9 show the effect of PVB material parameters on maximum principal stress. The material parameters have been normalized with respect to the baseline values (Table 1). Since the PVB is treated as linear elastic, only

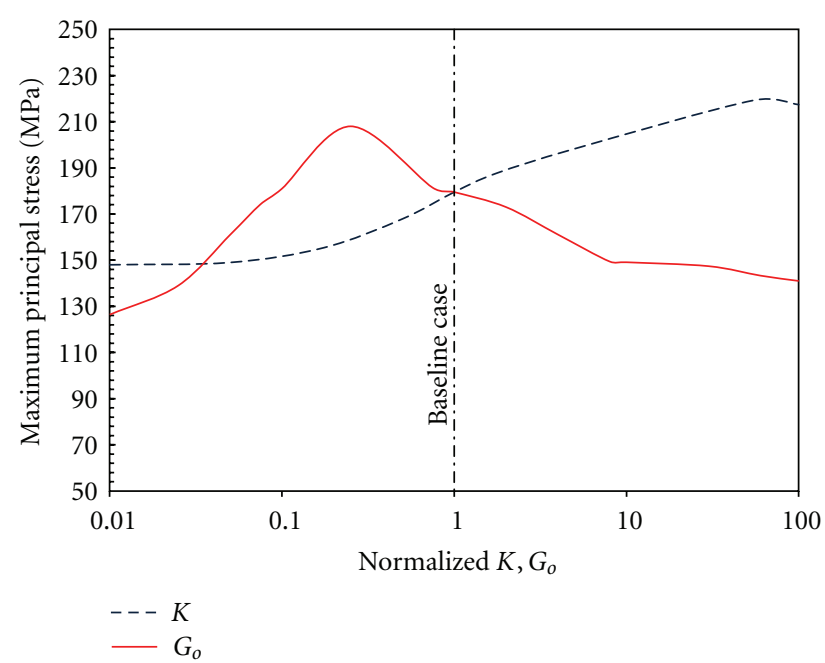

Figure 8: Effect of PVB properties (bulk modulus $K$ and short-term shear modulus $G_{o}$ ) on the maximum principal stress at the bottom surface of the inner ply for a small missile impact at a velocity of $39.62 \mathrm{~m} / \mathrm{s}$.

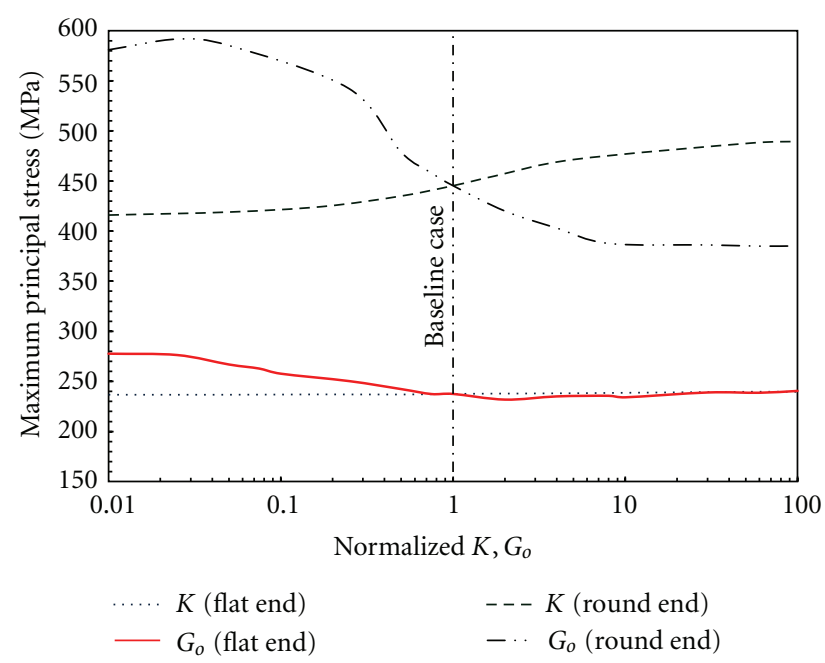

FIGURE 9: Effect of PVB properties (bulk modulus $K$ and short-term shear modulus $G_{o}$ ) on the maximum principal stress at the bottom surface of the inner ply for a large missile impact at a velocity of $58.11 \mathrm{~m} / \mathrm{s}$.

short-time shear modulus and bulk modulus are considered for the calculation of Young's modulus and Poisson's ratio. The effect of bulk modulus is more pronounced in the case of small missile impact than large missile with round end. There seems to be no effect on large missile with flat end. The effect of short-term shear modulus is seen in both small missile and large missile with round end clearly where as for large missile with flat end it is sensitive only at lower values. In case of small missile impact, for better impact resistance, it is better to have properties of bulk modulus and short-time shear modulus having two orders of magnitude lower than baseline case. 


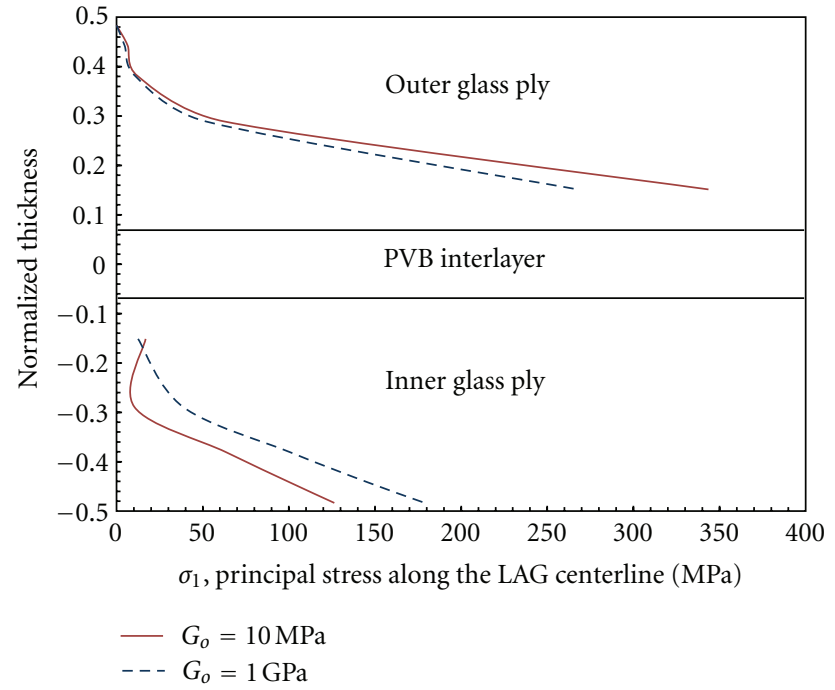

FIgURE 10: Maximum principal stress distribution through the thickness of LAG at its center for small missile impact at a velocity of $39.62 \mathrm{~m} / \mathrm{s}$.

Wei et al. [23] had studied the stress distribution through the thickness of laminated glazing subjected to blast loading. They observed that the stress distributions on the outer and inner plies are parallel but not collinear for low values of $G_{o}$ but becomes collinear as the $G_{o}$ value increases. Even though the maximum principal stress in the inner ply determines whether an LAG meets the "sacrificial ply" design requirement, it would be of interest to establish the stresses in the inner and outer glass plies at the glass/PVB interfaces as well as through thickness stress variation to ascertain that there are no anomalies. The maximum principal stress was determined at the LAG centerline $(x=0, y=0)$ for various values of coordinate $z$ (axis system shown in Figure 1) for the three missile cases. Figures 10, 11, and 12 show the maximum principal stress distribution in the $z$-direction, for high $(10 \mathrm{MPa})$ and low $(1 \mathrm{MPa})$ short-term shear moduli, along LAG centerline for the small missile impact and the large missile with round and flat end configuration, respectively. Though the stress distribution is not linear through the thickness of inner and outer glass plies, a parallel offset between the stress distribution in the inner and outer glass plies for low values of $G_{o}$ is observed.

This study so far dealt with missiles made of steel or wood. It is a common knowledge that the range of materials forming windborne debris varies widely. The debris, for example, could include pieces of roof shingles, glass fragments, steel nails and bolts, sand, metal rods, and pipes to name a few. In an attempt to assess the effect of missile material, the maximum principal stress was determined for small (spherical ball) and large missiles (cylindrical rod) made of different materials. Figure 13 shows the effect of mass density of debris on the principal stress at the bottom of the inner ply of laminated glazing. The mass density was normalized with respect to baseline mass density. For the small missile case, the normalized mass density $P$ is given by

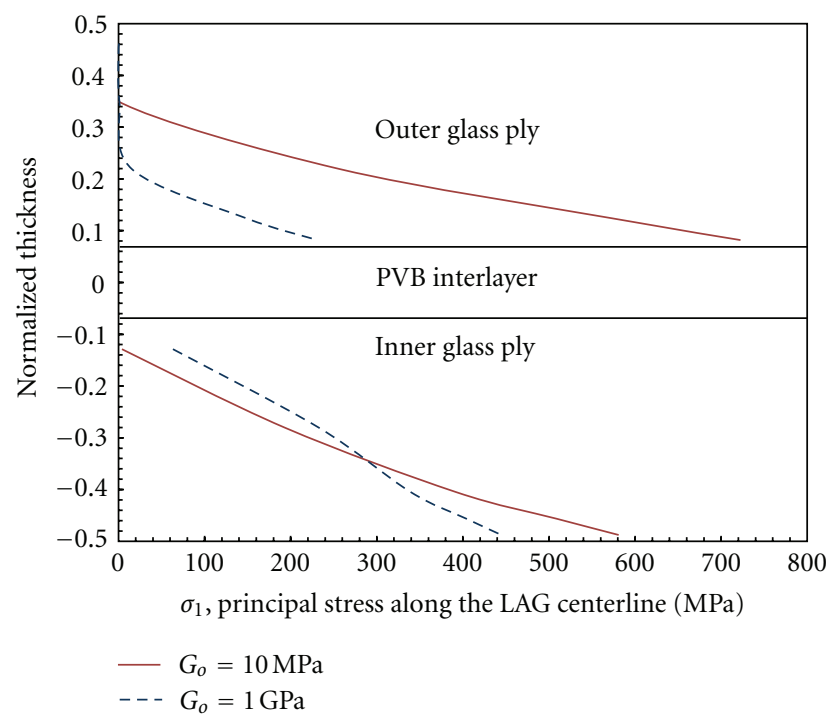

Figure 11: Maximum principal stress distribution through the thickness of LAG at its center for large missile impact at a velocity of $12.19 \mathrm{~m} / \mathrm{s}$ glazing for large (round end) missile impact.

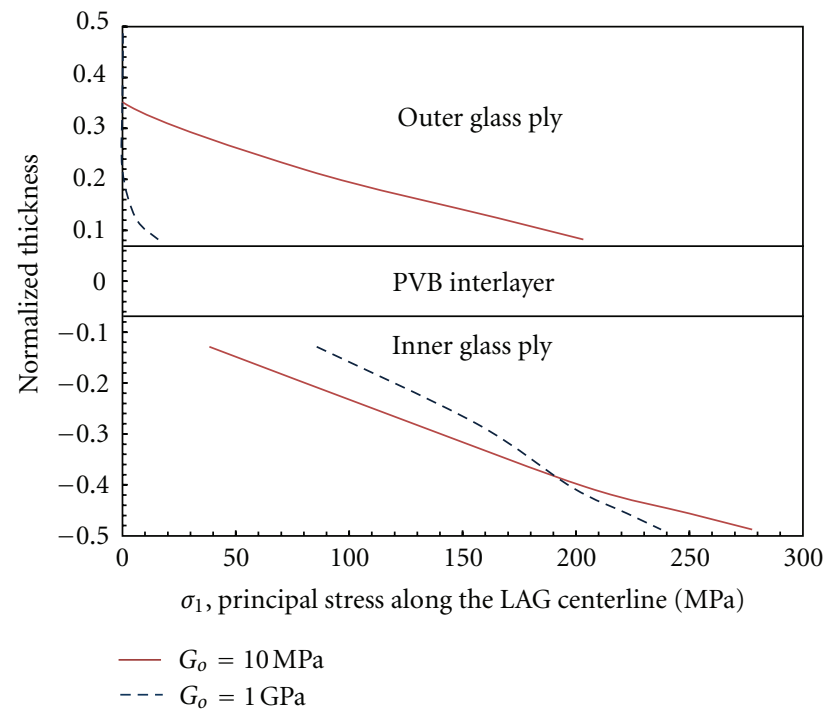

Figure 12: Maximum principal stress distribution through the thickness of LAG at its center for large missile impact at a velocity of $12.19 \mathrm{~m} / \mathrm{s}$ glazing for large (Flat end) missile impact.

$P=$ (mass density of the missile) $/($ mass density of steel). For the large missile case, the normalized mass density $P$ is given by $P=$ (mass density of the missile) $/$ (mass density of baseline wooden missile). The density range considered for small missile is between $2,660 \mathrm{~kg} / \mathrm{m}^{3}$ (granite) to $17,000 \mathrm{~kg} / \mathrm{m}^{3}$ (tungsten). In case of large missile, which is wood, the density varies between $200 \mathrm{~kg} / \mathrm{m}^{3}$ to $1,100 \mathrm{~kg} / \mathrm{m}^{3}$. The mass densities of light Douglas fir, which is about $505 \mathrm{~kg} / \mathrm{m}^{3}$ and that of steel, which is about $7,800 \mathrm{~kg} / \mathrm{m}^{3}$, fall within the range of densities considered in this study. For a completely elastic impact, the maximum interface force and hence the 


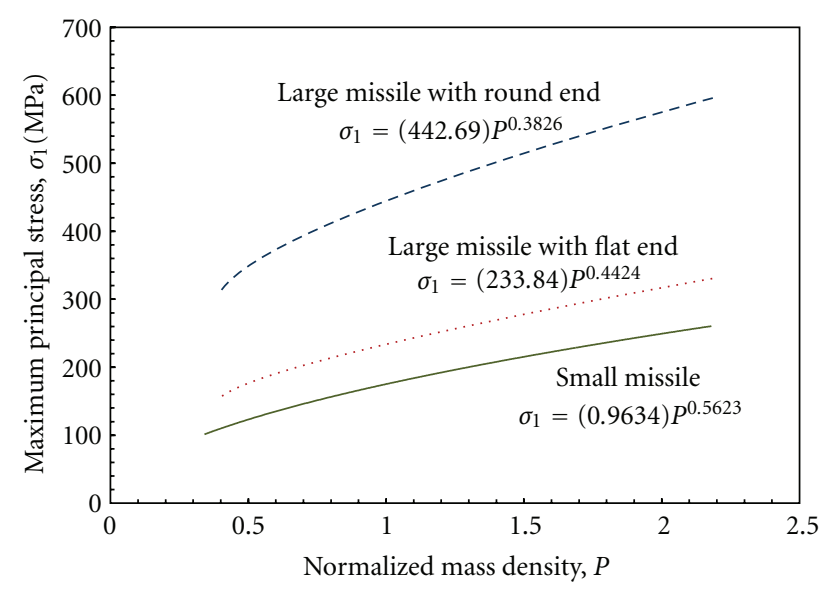

FIGURE 13: Effect of debris mass density on maximum principal stress at the bottom surface of the inner ply. Normalized mass density $=($ missile mass density $) /($ missile baseline density $)$.

maximum expected stress is proportional to $P^{3 / 5}$ [20]. From the power law fit equations in the figure, it can be seen that the small missile closely conforms to elastic impact, whereas large missile does not.

\section{Conclusion}

The main objective of this study was to study the stress response of rectangular laminated architectural glazing subjected to different impact loads in the presence of wind pressure. In particular it was to study the effects of geometry and material properties of the laminated glazing and determine the properties that reduce the possibility of inner ply fracture. The results provide a qualitative assessment of impact resistance of various LAG configurations based on the "sacrificial ply" design concept in which the inner glass is not allowed to fracture. Thinner outer ply would result in better prefailure stress pattern than a thicker outer ply. A thicker (PVB) interlayer generally results in lower stresses in failure critical areas. The contribution of wind loading to the principal stress is between $5-10 \%$ of the combined stress with small missile case having higher percentage. There is a similarity between stress responses of an LAG subjected to small missile impact and a large missile with round end. This is attributed to the nature of loading imparted by these two missile types on the LAG. This work serves as a precursor for the study of failure probability of inner ply of an LAG due to similar loading conditions.

\section{Notations}

E: Young's modulus

$v$ : Poisson's ratio

$\sigma_{i j}:$ Stress tensor

$S_{i j}$ : Deviatoric stress tensor

$p$ : Pressure

$\delta_{i j}:$ Kronecker delta

$\varepsilon_{i j}$ : Strain tensor

$\dot{\varepsilon}_{i j}$ : Deviatoric strain rate
$G(t)$ : Stress relaxation modulus

$G_{o}$ : Short-term shear modulus

$q$ : $\quad$ Pressure at height above the ground

G: $\quad$ Gust factor

$C_{p}$ : Pressure coefficient

$K_{z}$ : Velocity pressure co-efficient

$V: \quad$ Velocity of wind

I: Importance factor.

\section{References}

[1] W. L. Beason, G. E. Meyers, and R. W. James, "Hurricane related window glass damage in Houston," Journal of Structural Engineering, vol. 110, no. 12, pp. 2843-2857, 1984.

[2] J. E. Minor, "Lessons learned from failures of the building envelope in windstorms," Journal of Architectural Engineering, vol. 11, no. 1, pp. 10-13, 2005.

[3] F. W. Flocker and L. R. Dharani, "Stresses in laminated glass subject to low velocity impact," Engineering Structures, vol. 19, no. 10, pp. 851-856, 1997.

[4] F. W. Flocker and L. R. Dharani, "Modelling fracture in laminated architectural glass subject to low velocity impact," Journal of Materials Science, vol. 32, no. 10, pp. 2587-2594, 1997.

[5] F. W. Flocker and L. R. Dharani, "Modeling interply debonding in laminated architectural glass subject to low velocity impact," Structural Engineering and Mechanics, vol. 6, no. 5, pp. 485-496, 1998.

[6] F. W. Flocker and L. R. Dharani, "Low velocity impact resistance of laminated architectural glass," Journal of Architectural Engineering, vol. 4, no. 1, pp. 12-17, 1998.

[7] C. V. G. Vallabhan and G. D. Chou, "Stresses and displacements of window glass due to wind," in Proceedings of 5th U.S. National Conference on Wind Engineering, Texas Tech University, Lubbock, Tex, USA, 1985.

[8] A. V. Duser, A. Jagota, and S. J. Bennison, "Analysis of glass/polyvinyl butyral laminates subjected to uniform pressure," Journal of Engineering Mechanics, vol. 125, no. 4, pp. 435-442, 1999.

[9] L. R. Dharani, F. Ji, R. A. Behr, J. E. Minor, and P. A. Kremer, "Breakage prediction of laminated glass using the "sacrificial ply" design concept," Journal of Architectural Engineering, vol. 10, no. 4, pp. 126-135, 2004.

[10] F. S. Ji, L. R. Dharani, and R. A. Behr, "Damage probability in laminated glass subjected to low velocity small missile impacts," Journal of Materials Science, vol. 33, no. 19, pp. 47754782, 1998.

[11] N. D. Kaiser, R. A. Behr, J. E. Minor, L. R. Dharani, F. S. Ji, and P. A. Kremer, "Impact resistance of laminated glass using "sacrificial ply" design concept," Journal of Architectural Engineering, vol. 6, no. 1, pp. 24-34, 2000.

[12] C. R. Tsai and R. A. Stewart, "Stress analysis of large deflection of glass plates by the finite element method," Journal of the American Ceramic Society, vol. 59, no. 9-10, pp. 445-448, 1976.

[13] T. J. Saxe, R. A. Behr, J. E. Minor, L. R. Dharani, and P. A. Kremer, "Effects of missile size and glass type on impact resistance of "Sacrificial ply" laminated glass," Journal of Architectural Engineering, vol. 8, no. 1, pp. 24-39, 2002.

[14] L. R. Dharani and J. Yu, "Failure modes of glass panels subjected to soft missile impact," in Damage and Fracture Mechanics VIII, C. A. Brebbia and A. Varvani- Farahani, Eds., pp. 163171, WIT Press, Southampton, UK, 2004. 
[15] J. L. Glathart and F. W. Preston, "Behavior of glass under impact: theoretical considerations," Journal of Glass Technology, vol. 9, no. 4, pp. 9-22, 1968, http://ceramics.org/.

[16] L. R. Dharani, J. Wei, J. Yu, J. E. Minor, R. A. Behr, and P. A. Kremer, "Laminated architectural glass subjected to blast, impact loading," American Ceramic Society Bulletin, vol. 84, no. 1, pp. 42-44, 2005.

[17] ASCE, Minimum Design Loads For Buildings and Other Structures, American Society of Civil Engineers, Reston, Va, USA, 2006.

[18] ASTM, "Standard test method for performance of exterior windows, curtain walls, doors and impact protective systems impacted by missile(s) and exposed to cyclic pressure differentials," E1886-05, ASTM STP International, West Conshohocken, Pa, USA, 2005.

[19] ASTM, "Standard specification for performance of exterior windows, curtain walls, doors and impact protective systems impacted by missile(s) and exposed to cyclic pressure differentials," E1996-08, ASTM STP International, West Conshohocken, Pa, USA, 2008.

[20] F. Ghrib and R. Tinawi, "An application of damage mechanics for seismic analysis of concrete gravity dams," Earthquake Engineering \& Structural Dynamics, vol. 24, no. 2, pp. 157-173, 1995.

[21] J. Wei and L. R. Dharani, "Fracture mechanics of laminated glass subjected to blast loading," Theoretical and Applied Fracture Mechanics, vol. 44, no. 2, pp. 157-167, 2005.

[22] Simulia, ABAQUS Explicit/Standard User'S Manual, Version 6. 7, Hibbit, Karlsson and Sorenson, 2008.

[23] J. Wei, M. S. Shetty, and L. R. Dharani, "Stress characteristics of a laminated architectural glazing subjected to blast loading," Computers \& Structures, vol. 84, no. 10-11, pp. 699-707, 2006. 

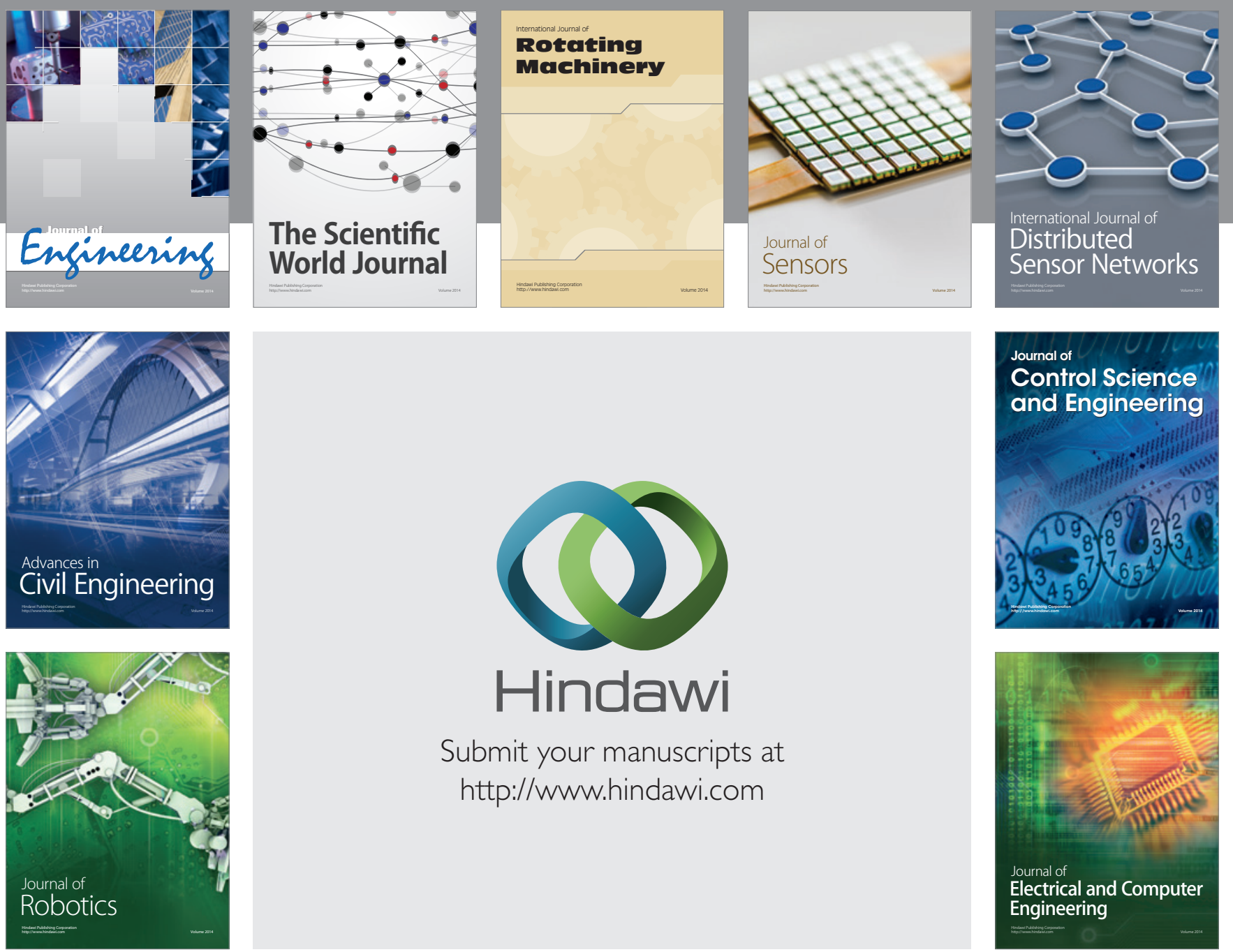

Submit your manuscripts at

http://www.hindawi.com
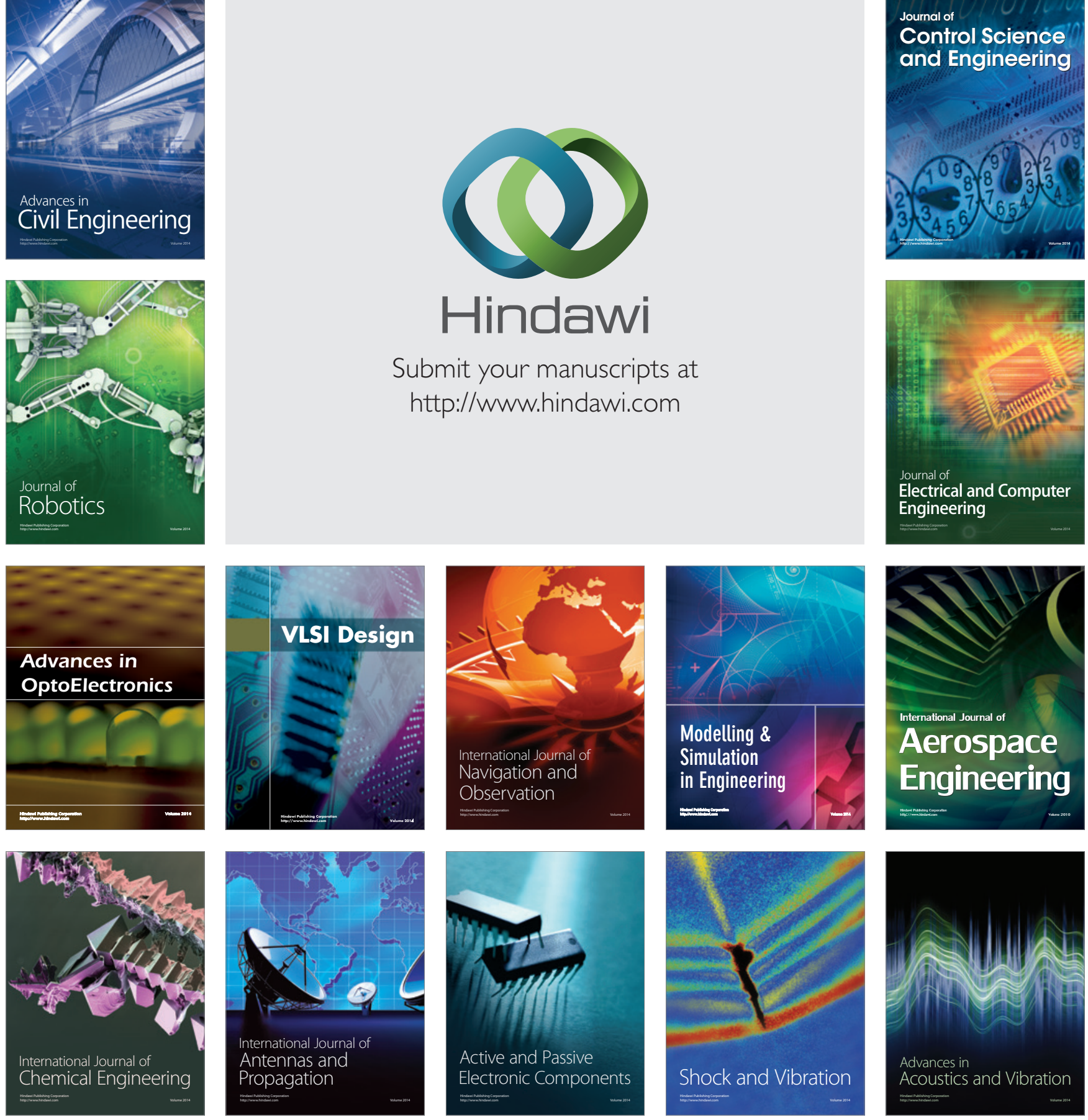